\title{
Daratumumab Interference in Pretransfusion Testing Is Overcome by Addition of Daratumumab Fab Fragments to Patients' Plasma
}

\author{
Egon Werle Josefin Ziebart Eleonora Wasmund Kristin Eske-Pogodda \\ Institute of Laboratory Diagnostics, Microbiology, and Transfusion Medicine, Dietrich-Bonhoeffer-Klinikum, \\ Neubrandenburg, Germany
}

\author{
Keywords \\ Daratumumab · Pretransfusion testing $\cdot$ CD38 . \\ Fab fragments $\cdot$ Interference
}

\begin{abstract}
Background: Daratumumab (DARA), an $\lg \mathrm{G} 1 \mathrm{~K}$ human monoclonal anti-CD38 antibody, is used for the treatment of refractory myeloma for example. Binding of DARA to CD38 on red blood cells (RBCs), however, leads to panagglutination in indirect antiglobulin testing and possibly masks clinically relevant alloantibodies. Dithiothreitol eliminates panreactivity by destroying CD38 but has the drawback of modifying certain blood group antigens and, thereby, impairs the detection of alloantibodies. Methods: DARA was digested for $16 \mathrm{~h}$ at $37^{\circ} \mathrm{C}$ using immobilized papain in a spin column, centrifuged, and washed, and the DARA-Fab fragments in pooled flow-throughs were stored at $-20^{\circ} \mathrm{C}$. DARA-Fab and test cells (ID-DiaCell I-II-III or ID-DiaPanel; BioRad) were incubated with human plasma spiked with DARA (plasma concentration up to $1,000 \mathrm{mg} / \mathrm{L}$ ) or plasma from patients under DARA therapy at $37^{\circ} \mathrm{C}$ for $15 \mathrm{~min}$. Thereafter, ID-Cards LISS/Coombs were used. Results: Immunofixation electrophoresis showed complete fragmentation of DARA into Fc and Fab fragments by papain proteolysis. DARA-Fab efficiently prevented RBC agglutination by patients' plasma and by plasma spiked with DARA. Moreover, DARA-Fab did not interfere with the detection of alloantibodies. Conclusion: We present a quite easy, reproducible, and cost-effective method for DARA-Fab fragment
\end{abstract}

() 2019 S. Karger AG, Basel preparation. Blocking CD38 epitopes with DARA-Fab easily overcomes DARA interference in pretransfusion testing without affecting alloantibody detection.

(c) 2019 S. Karger AG, Basel

\section{Introduction}

Daratumumab (DARA) is a human monoclonal IgG1 $\kappa$ antibody used for the treatment of multiple myelomas and other hematological tumors increasing in frequency [1]. The antibody binds to CD38 which is expressed on lymphoid and myeloid cells $[2,3]$. Therapeutic monoclonal antibodies may disturb laboratory diagnostics. DARA interferes, for example, with myeloma cell detection by flow cytometry [4] and disturbs the detection and quantitation of monoclonal proteins by immunofixation electrophoresis (IFE). The latter problem could be solved by use of a specific anti-DARA antibody [5]. Patients treated with DARA often develop anemia with progressing disease or following chemotherapy [1]. Since CD38 is also expressed at low levels on red blood cells (RBCs), DARA causes positive reactions in indirect antiglobulin tests (IATs), e.g., antibody detection (screening) tests, antibody identification panels, and antihuman immunoglobulin crossmatches. Typically, there is no reactivity of patients' plasma with patients' RBCs in antihuman immunoglobulin (autocontrol) since CD38 expression is downregulated during treatment, thereby preventing hemolysis in vivo [6]. To overcome interference of DARA 
in alloantibody screening, treatment of test cells with dithiothreitol (DTT) is widely used in serological laboratories [7]. DTT denaturates CD38 on the cell surface by reducing disulfide bonds. However, DTT also destroys or modifies some other blood group antigens, e.g., KEL, DO, JMH, LU, IN, and YT [8], which results in impaired sensitivity to detect alloantibodies against these blood group antigens. There are several recommendations on how to deal with this problem, such as extending RBC phenotyping to $\geq 3$ months after any recent blood transfusion or genotyping prior to DARA treatment [9]. Only recently, a modified method for DTT treatment to reduce the hemolysis up to 28 or even 33 days of storage was published $[10,11]$. Use of papain-treated cell panels also exhibited severe limitations [12]. An alternative approach is blocking the binding site of DARA with soluble CD38 peptides [13], which, however, is too expensive for routine testing. Blocking of the antigen binding site of DARA by incubation of patients' plasma with anti-idiotypic antibodies may also be intriguing; however, these antibodies are not commercially available [14]. In addition, umbilical cord RBCs as screening cells are not typically available in a routine transfusion laboratory, and, furthermore, cord cells may have altered expression of some antigens [9]. In a recently published case report, a commercially available product was used to prevent DARA interference in IAT [15]. In summary, pretreatment of RBCs with DTT is still performed in most laboratories as recommended by Chapuy et al. [7] in 2015, and it is widely used despite the above-mentioned drawbacks until today.

In summer 2017, we started experiments and developed a novel and simple method to overcome DARA interference by blocking the CD38 epitopes on RBCs by DARA-Fab fragments (DARA-Fab) which were generated by papain proteolysis of DARA antibodies. This method was validated since autumn 2017 in our laboratory in parallel to the DTT treatment. Simultaneous incubation of patients' plasma and DARA-Fab with screening cells prevented panagglutination in pretransfusion testing without affecting the detectability of all alloantibodies tested. This procedure is cost-effective and very suitable for routine serological testing.

\section{Materials and Methods}

\section{Effect of DARA on IAT}

The agglutination potential of DARA in IAT was demonstrated by incubation of $50 \mu \mathrm{L} 0.8 \%$ ID-DiaCell I-II-III screening cells (BioRad, Hercules, CA, USA) with $25 \mu \mathrm{L}$ standard human plasma (SHP; Siemens, Erlangen, Germany) spiked with DARA (Darzalex $^{\circledR}$; Janssen, Beerse, Belgium). DARA plasma concentrations (ranging from $200 \mathrm{mg} / \mathrm{L}$ to $1.5 \mu \mathrm{g} / \mathrm{L}$ ) were prepared by serial dilution of $200 \mathrm{mg} / \mathrm{L}$ DARA in SHP. IAT was performed using IDCards LISS/Coombs (BioRad) containing polyspecific anti-IgG and anti-C3d antibodies within the gel matrix. The ID-Cards were incubated at $37^{\circ} \mathrm{C}$ for $15 \mathrm{~min}$ in an ID-incubator $37 \mathrm{SI}$ (BioRad) and afterwards centrifuged in an ID-centrifuge 12 SII (BioRad) for $10 \mathrm{~min}$ at $1,030 \mathrm{rpm}$. Agglutination of RBCs was evaluated by assigning the numbers 0 (no agglutination), $0.5+$ (very weak agglutination), 1+ (weak agglutination), 2+ (moderate agglutination), $3+$ (strong agglutination), and 4+ (very strong agglutination).

\section{IgG Subclass Measurement before and after DARA}

Administration

$I_{g} G_{1}, I g G_{2}, I g G_{3}$, and $I_{g G}$ levels before and 1 day after Darzalex ${ }^{\circledR}$ administration were measured in plasma samples with latex-enhanced immunonephelometry (BN ProSpec analyzer, N AS IgG1/2/3/4 reagents; Siemens Healthcare Diagnostics GmbH, Eschborn, Germany).

\section{DARA-Fab Preparation}

Fab fragments were generated from Darzalex ${ }^{\circledR}$ using the Pierce $^{\mathrm{TM}}$ Fab preparation kit (No. 44985; Thermo Scientific, Waltham, MA, USA) according to manufacturer's instructions with minor modifications. Briefly, $250 \mu \mathrm{L}$ immobilized papain solution were placed into a $0.8-\mathrm{mL}$ spin column, and buffer was discarded by centrifugation at $4,125 \mathrm{~g}$ for $2 \mathrm{~min}$. Digestion buffer was prepared directly before use by dissolving $3.5 \mathrm{mg}$ cysteine $\mathrm{HCl}$ in Fab digestion buffer. Resin was washed with $0.5 \mathrm{~mL}$ digestion buffer by centrifugation of columns at 4,125 $\mathrm{g}$ for $2 \mathrm{~min}$. Subsequently, 100 $\mu \mathrm{L}$ of DARA ( $2 \mathrm{mg}$ ) and $400 \mu \mathrm{L}$ digestion buffer were mixed and added to the spin column. Antibodies were digested for $16 \mathrm{~h}$ at $37^{\circ} \mathrm{C}$ by constantly inverting the recapped spin column. DARAFab were extracted by centrifugation at $4,125 \mathrm{~g}$ for $2 \mathrm{~min}$. Resin was washed with $100 \mu \mathrm{L}$ phosphate-buffered saline (PBS; pH 7.2), and pooled flow-throughs were stored at $-20^{\circ} \mathrm{C}$. Digestion was controlled by IFE using a Hydrasys 2 scan with the Hydragel 4 IF kit (Sebia, Évry, France). Native DARA (20 g/L) diluted 1:20 and undiluted DARA-Fab solution were mixed 1:2 with Hydragel IF diluent, and $10 \mu \mathrm{L}$ of the dilution were applied to the gel per track. For immunofixation, anti- $\gamma$ heavy-chain and anti- $\kappa$ light-chain antisera were used for both native and digested DARA, and staining was done with IF acid violet (Sebia). DARA-Fab purification with the $\mathrm{NAb}^{\mathrm{TM}}$ Protein A Plus Spin Column of the Pierce ${ }^{\mathrm{TM}} \mathrm{Fab}$ preparation kit was done once but omitted thereafter as discussed later on.

\section{DARA-Fab Testing}

To test the efficiency of DARA-Fab to mask CD38 on RBCs, 15 $\mu \mathrm{L}$ of DARA-Fab and $50 \mu \mathrm{L}$ of $0.8 \%$ ID-DiaCell I-II-III screening cells or the ID-DiaPanel (a set of 11 panel cells) for antibody identification (BioRad) were incubated simultaneously with $25 \mu \mathrm{L} \mathrm{SHP}$ spiked with DARA (concentrations of 100, 250, 500, or 1,000 mg/L in SHP) or with $25 \mu \mathrm{L}$ of plasma from DARA-treated patients $(n=$ 8 , age: $71 \pm 7$ years). Incubation was done in glass tubes in a $37^{\circ} \mathrm{C}$ water bath for $15 \mathrm{~min}$. Cells were agitated several times to prevent pelleting of erythrocytes and to facilitate the binding DARA-Fab to CD38 epitopes. A whole cell suspension was transferred to the microcolumn of an ID-Card LISS/Coombs and centrifuged for 10 $\mathrm{min}$ at $1,030 \mathrm{rpm}$. Agglutination of RBCs was evaluated by assigning the numbers $0-4+$ as described above. In case of incomplete inhibition of DARA binding to test cells, the DARA-Fab volume was increased to $30 \mu \mathrm{L}$.

Adding $30 \mu \mathrm{L}$ DARA-Fab significantly reduces the DARA concentration and may contribute to the negative results. Therefore, we also tested a modified pipetting scheme: $50 \mu \mathrm{L} 1.4 \% \mathrm{RBCs}, 40$ $\mu \mathrm{L}$ SHP, $5 \mu \mathrm{L}$ DARA $(3.5 \mathrm{~g} / \mathrm{L})$, and $30 \mu \mathrm{L}$ DARA-Fab. This mixture results in nearly identical relative RBC and DARA concentrations in a final volume of $125 \mu \mathrm{L}$ as recommended in the validated instructions from BioRad (25 $\mu \mathrm{L}$ patients' plasma and $50 \mu \mathrm{L} 0.8 \%$ RBC solution). 
Flow Cytometry

Flow cytometry was performed with ID-DiaPanel cells in order to be able to refer the extent of the reactivity of DARA-spiked SHP in IAT to the expression of CD38 on the cell surface of RBCs. Test cells $\left(10^{6} /\right.$ tube) were stained in PBS containing $2.5 \%$ fetal calf serum in a total volume of $50 \mu \mathrm{L}$ using mouse antihuman CD38 phycoerythrin-Texas red (ECD, A99022; Beckman Coulter, Brea, CA, USA). As isotype control, cells were incubated with mouse $\mathrm{IgG}_{1}$ ECD (A07797; Beckman Coulter) in a separate tube. Incubation with antibodies was performed at room temperature for 30 min protected from light. Afterwards, cells were washed twice and resuspended in $200 \mu \mathrm{L}$ BD CellWash. Measurement of a total of $1 \times 10^{5}$ cells was performed with a Navios ${ }^{\mathrm{TM}} 10$-color flow cytometer (Beckman Coulter). Evaluation of flow-cytometric data was performed with Kaluza ${ }^{\circledR}$ software (version 1.5a; Beckman Coulter). The differences between the median fluorescence intensity (MFI) of anti-CD38-labeled RBCs and the MFI of the isotype control were calculated and compared to the reaction strength of DARA-spiked SHP in IAT in these panel cells.

CD38 density has been described for CD8+ lymphocytes [16] but not for RBCs. Therefore, we stained CD38 on RBCs and on CD8+ lymphocytes of healthy patients ( $n=6$; age $41 \pm 13$ years) to estimate the CD38 density on RBCs by calculating the anti-CD38 MFI (CD8+) quotient and the anti-CD38 MFI (RBC) quotient and referring the quotient to the number of CD38 on CD8+ lymphocytes described in the literature. Whole blood $(200 \mu \mathrm{L})$ was incubated with mouse antihuman CD8 FITC (A07756; Beckman Coulter) and mouse antihuman CD38 ECD or mouse IgG $_{1}$ ECD at room temperature for $30 \mathrm{~min}$ protected from light. Cells were washed twice and resuspended in $200 \mu \mathrm{L}$ BD CellWash. For analysis of CD38 on RBCs, $10 \mu \mathrm{L}$ of the cell suspension were diluted 1 : 20 in CellWash. The residual volume was treated with lysing solution (VersaLyse, A09777; Beckman Coulter) for $10 \mathrm{~min}$ at room temperature, washed once, and resuspended in $200 \mu \mathrm{L}$ CellWash for measurement of CD8+ cells.

\section{Irregular Antibody Screening}

Fifty microliters of ID-DiaCell I-II-III cells and ID-DiaPanel (BioRad) cells were incubated with $25 \mu \mathrm{L}$ plasma from patients with an irregular alloantibody (anti-E, anti-K, anti-c, anti-D, anti$\mathrm{M}$, and anti-Fy[a]). Moreover, these native plasma samples were tested in parallel after spiking with DARA $(20 \mathrm{~g} / \mathrm{L})$ to give a final DARA concentration of $500 \mathrm{mg} / \mathrm{L}$ in the patients' plasma. Finally, the patients' plasma samples, spiked with DARA, were incubated with DARA-Fab $(15 \mu \mathrm{L})$. Thereby, the ability of DARA-Fab to prevent panreactivity without altering the reaction pattern and reaction strength of the alloantibodies was evaluated.

In addition, we tested the possible influence of DARA-Fab on the sensitivity to detect alloantibodies with commercially available test sera using the Data-Cyte ${ }^{\circledR}$ Plus panel (Grifols, Frankfurt, Germany).

For these experiments, we used a modified pipetting scheme to exclude that the dilution of RBCs and alloantibodies by the addition of an increased volume of DARA-Fab $(15$ or $30 \mu \mathrm{L})$ may influence the detection limit of alloantibodies. Adjustments were drafted to ensure a concentration of plasma which may contain alloantibodies and a concentration of RBC in the final volume identical to the original pipetting scheme. This was realized by an increased final volume.

We used $50 \mu \mathrm{L}$ Grifols panel cells for antibody identification adjusted to $1.4 \%, 40 \mu \mathrm{L}$ test serum, $5 \mu \mathrm{L}$ DARA $(3.5 \mathrm{~g} / \mathrm{L})$ diluted in SHP (equal to $500 \mathrm{mg} / \mathrm{L}$ DARA concentration in patients' plasma), and $15 \mu \mathrm{L}$ DARA-Fab. SHP was added to give a final volume of 125 $\mu \mathrm{L}$. In a few cases, we had to add $30 \mu \mathrm{L}$ DARA-Fab in a final volume of $125 \mu \mathrm{L}$ (without SHP). We tested the reaction pattern and

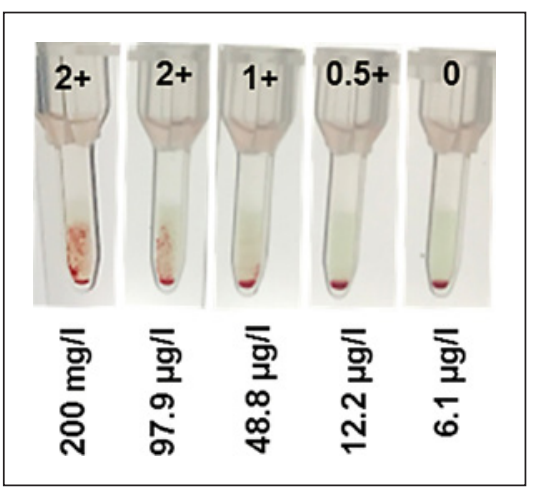

2

Fig. 1. Serial dilution of $200 \mathrm{mg} / \mathrm{L}$ DARA in standard human plasma demonstrates capability of DARA to agglutinate screening cells in indirect antiglobulin testing down to a concentration of $12.2 \mu \mathrm{g} / \mathrm{L}$.

Fig. 2. Immunofixation electrophoresis of native and papain-digested DARA. The gel shows complete digestion of the antibodies resulting in the fragmentation into the Fc region detected by anti- $\gamma$ heavy-chain antiserum $(G)$ and DARA-Fab fragments detected by anti- $\kappa$ light-chain antiserum $(\mathrm{K})$.

strength of the test sera with or without addition of DARA and with or without addition of DARA-Fab.

Test sera were diluted with SHP in order to give a reactivity strength of about $2+$. The following antibodies were used (distributor, lot number, sell-by date, dilution): anti-Jk(a) (SD Nostik, 1Ja043, 05-2019, 1:8), anti-Jk(b) (Biolith, 504k, 10-2019, 1:3), antiFy(a) (Optima, T04616, 03-2019, 1:30), anti-Fy(b) (SD Nostik, 2Fb004, 07-2019, 1:30), anti-S (Optima, P26316, 06-2019, 1:30), anti-s (Optima, F06441, 06-2019, 1:30), anti-Le(a) (Optima, S06771, 06-2019, 1:8), anti-Lu(a) (Biolith, 507S, 12-2018, 1:5), anti-Kp(a) (SD Nostik, 2Ra026, 07-2019, 1:10), anti-C (Biolith, 302kMS24, 05-2018, 1:1,000), anti-e (Optima, H93641, MS-16/ $-21 /-63,1: 500)$, and anti-C(w) (Biolith, 204K, 01-2019, 1:5).

\section{Results}

Measuring the $\operatorname{IgG}_{1}$ serum concentration by nephelometry 1 day after administration of $16 \mathrm{mg} / \mathrm{kg}$ Darzalex resulted in a relative increase of about $200-400 \mathrm{mg} / \mathrm{L} \mathrm{IgG}_{1}$ as expected [17].

SHP, spiked with $200 \mathrm{mg} / \mathrm{L}$ DARA, was serially diluted to ascertain the minimum DARA concentration necessary to induce agglutination of erythrocytes in IAT (Fig. 1). Up to $97.7 \mu \mathrm{g} / \mathrm{L}$ DARA induced a $2+$ reaction. Diminution of the reaction was first seen with $48.8 \mu \mathrm{g} / \mathrm{L}$. Complete loss of RBC agglutination was shown at a DARA concentration of $6.1 \mu \mathrm{g} / \mathrm{L}$.

Papain proteolysis of $2 \mathrm{mg}$ DARA for $16 \mathrm{~h}$ at $37^{\circ} \mathrm{C}$ under continuous inverting was very effective. IFE of native and papain-digested DARA antibodies shows complete fragmentation of DARA into Fc and Fab fragments detected by anti- $\gamma$ heavy-chain and anti- $\kappa$ light-chain antiserum, respectively (Fig. 2). 
Fig. 3. Incubation of screening cells with $100,250,500$, and $1,000 \mathrm{mg} / \mathrm{L}$ DARA in standard human plasma resulted in a strong agglutination of erythrocytes. Simultaneous incubation of screening cells with $15 \mu \mathrm{L}$ DARA-Fab with DARA inhibited the agglutination reaction efficiently. w/o, without.
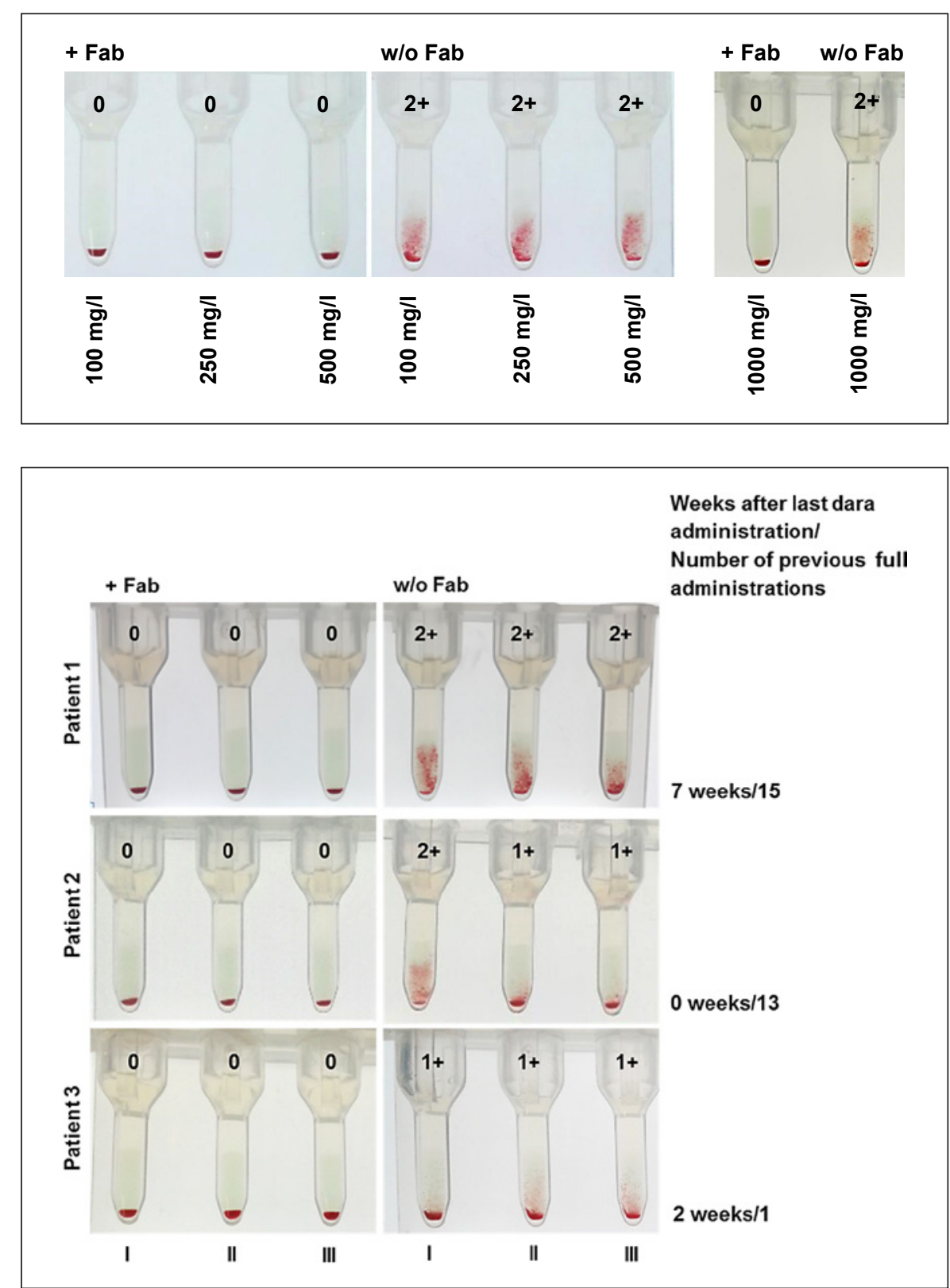

Fig. 4. Plasma of myeloma patients treated with DARA resulted in agglutination of screening cells (I, II, III). Simultaneous incubation of screening cells with $15 \mu \mathrm{L}$ DARA-Fab inhibited the agglutination reaction efficiently. In patients 1,2 , and 3 , blood was drawn 7, 0, and 2 weeks after the last DARA administration and after 15, 13, and 1 full DARA administrations, respectively.
The protocol allowed the reproducible generation of DARA-Fab fragments, ready to use for incubation with test cells without further purification steps. According to our experience, elimination of Fc fragments by absorption to protein A should not have a measurable effect on DARA-Fab results in IAT. DARA-Fab activity was maintained after storage at $-20^{\circ} \mathrm{C}$ for several months. Spin columns containing immobilized papain can be stored in PBS at $4^{\circ} \mathrm{C}$ for several weeks without decreasing efficiency of Fab generation when columns are washed with digestion buffer prior to new digestion. The complete DARA fragmentation was verified after each DARA-Fab production by IFE.

Efficiency of CD38 masking by DARA-Fab fragments was first tested exemplarily in a few screening cells incu- bated with SHP spiked with DARA obtaining the following final concentrations: $100,250,500$, and $1,000 \mathrm{mg} / \mathrm{L}$ (Fig. 3); $15 \mu$ L DARA-Fab were sufficient to prevent binding of DARA to these cells and RBC agglutination at all DARA concentrations.

Furthermore, all 3 ID-DiaCell I-II-III screening cells were incubated with the plasma of the 8 patients receiving DARA therapy. Simultaneous incubation of cells with 15 $\mu \mathrm{L}$ Fab resulted in overriding of DARA-induced panagglutination. Representative results of 3 patients are shown in Figure 4.

A set of 11 ID-DiaPanel cells for antibody identification (BioRad) was incubated with SHP spiked with DARA $(500 \mathrm{mg} / \mathrm{L})$ with or without simultaneous addition of 15 or $30 \mu \mathrm{L}$ DARA-Fab and, thereafter, applied to ID-Cards 


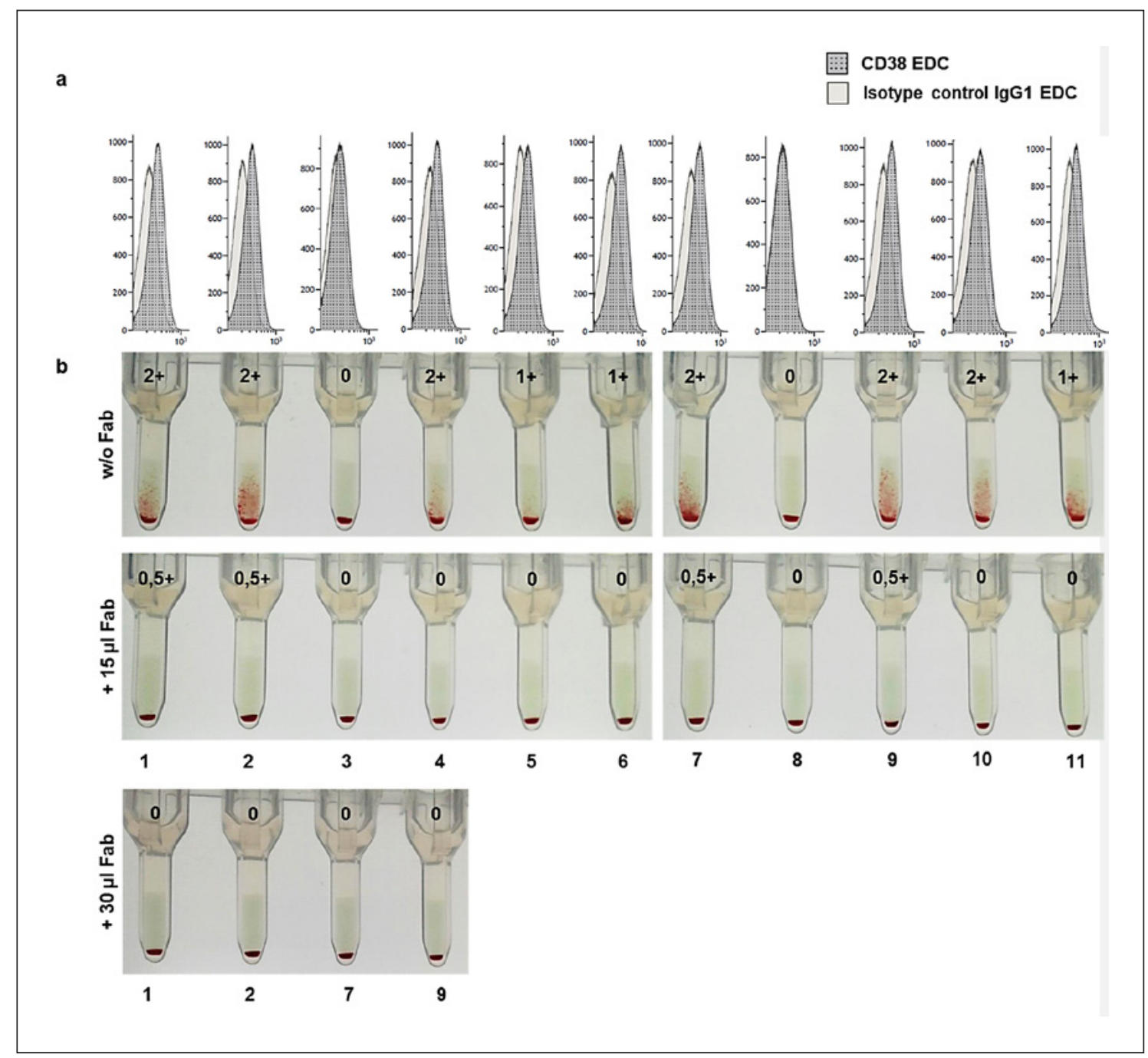

Fig. 5. Comparison of the CD38 expression and the respective isotype control on ID-DiaPanel cells shows low CD38 expression with varying density on RBCs (a). Indirect antiglobulin test of ID-DiaPanel cells incubated with $500 \mathrm{mg} / \mathrm{L}$ DARA in standard human plasma (w/o Fab) and panel cells incubated simultaneously with $500 \mathrm{mg} / \mathrm{L}$ DARA and 15 or $30 \mu \mathrm{L}$ DARA-Fab (b). DARA-Fab prevents DARA-induced agglutination of erythrocytes in a dose-dependent manner.

LISS/Coombs and centrifuged (Fig. 5). Two panel cells (3 and 8) did not react with DARA. Very low expression of CD38 on these cells was confirmed by flow cytometry (MFI $22 \pm 25$ ). ID-DiaPanel cells 4-6, 10, and 11 showed $1+$ or $2+$ reactions, which could be prevented by addition of $15 \mu \mathrm{L}$ DARA-Fab solution. The agglutination of the ID-DiaPanel cells 1, 2, 7, and 9, which all exhibited 2+ reactions, were strongly reduced showing only very slight RBC agglutination (0.5+ reaction or below). For these cells, the experiment was repeated using $30 \mu \mathrm{L}$ DARAFab solution resulting in complete prevention of agglutination. Despite different reactivity of identification cells to DARA, flow cytometry showed similar MFI for cells exhibiting $1+$ and $2+$ reactions $(103 \pm 20$ and $105 \pm 10$, respectively).
To estimate CD38 density on RBCs, we stained CD38 on RBCs and on CD8+ cells in blood samples of healthy individuals and compared the MFI of anti-CD38 on both cell types. CD8+ cells showed an anti-CD38 MFI of $1,643 \pm 969$ while RBCs exhibited an anti-CD38 MFI of $139 \pm 31$. Therefore, we hypothesized that the CD38 density on RBSs is about 10 times lower than on CD8+ cells.

Incubation of test cells with DARA-Fab fragments prevented panagglutination of screening cells and did not interfere with the detection of alloantibodies or result in false-positive results in negative screening cells. This is shown with patients' plasma containing anti-K and anti-E antibodies which were additionally spiked to give a final plasma concentration of $500 \mathrm{mg} / \mathrm{L}$ DARA (Fig. 6). The same was true for patients' plasma containing alloanti- 




Fig. 6. Reactivity of screening cells with plasma from patients with an anti-E or anti-K alloantibody without or spiked with $500 \mathrm{mg} / \mathrm{L}$ DARA. Lower figures show screening cells incubated with $15 \mu \mathrm{L}$ DARA-Fab and patient's plasma containing an anti-E or anti-K alloantibody and $500 \mathrm{mg} / \mathrm{L}$ DARA. DARA-Fab incubation does not interfere with recognition of alloantibodies.

bodies directed against the blood group antigens $\mathrm{c}, \mathrm{D}, \mathrm{M}$, and Fy(a) (data not shown).

We further tested alloantibody detection using a modified pipetting scheme to guarantee that the detection sensitivity for alloantibodies is not at all impaired by the addition of DARA-Fab and/or DARA spike solution. The detection limit of alloantibodies is expected to be unchanged because the concentration of plasma which may contain alloantibodies and the RBC concentration are identical despite an increased final volume. We found no significant differences in the reaction strength of alloantibodies when we compared the results without or with the simultaneous addition of DARA spike solution and DARA-Fab. In detail, DARA-Fab did not reduce the reaction strength of these test sera: $\operatorname{Jk}(\mathrm{a}), \mathrm{Jk}(\mathrm{b}), \mathrm{Fy}(\mathrm{a})$, $\mathrm{Fy}(\mathrm{b}), \mathrm{S}, \mathrm{s}, \mathrm{Le}(\mathrm{a}), \operatorname{Lu}(\mathrm{a}), \mathrm{Kp}(\mathrm{a}), \mathrm{C}, \mathrm{e}$, and $\mathrm{C}(\mathrm{w})$. We also compared this modified pipetting scheme with the "standard" scheme $(50 \mu \mathrm{L}$ RBC $0.8 \%, 25 \mu \mathrm{L}$ plasma \pm DARA, $\pm 15 \mu$ LARA-Fab) and also found no significant effect of plasma dilution on the reaction strength as shown in Figure 6.

\section{Discussion}

DARA, a monoclonal $\operatorname{IgG}_{1}$ type $\kappa$ antibody directed against CD38, successfully depletes CD38-expressing myeloma cells. RBCs physiologically express low levels of CD38, which result in panagglutination of RBCs in serological testing and, thereby, complicate alloantibody detection and compatibility testing [17]. Erythrocytes in subjects receiving DARA treatment are supposed to be protected from hemolysis by downregulation of CD38 which manifests in a negative direct antiglobulin testing and a negative autocontrol in these patients. A slight decrease in hemoglobin levels, however, has been suggested $[1,13]$.

The DARA-Fab preparation described in the present paper is quite easy and requires no special equipment. Purification, i.e., elimination of Fc fragments by use of protein $\mathrm{A}$, is not necessary because $\mathrm{Fc}$ fragments do not interfere with DARA and DARA-Fab binding to RBCs during the incubation. Moreover, when adding the mixture of RBCs, DARA, and DARA-Fab onto the microcolumns of the gel card, the low amount of $\mathrm{Fc}$ fragments as compared to the patients' plasma IgG concentration is not expected to disturb the detection of RBC-bound antibodies by antihuman immunoglobulin.

We decided to use papain proteolysis resulting in the cleavage of DARA into $1 \mathrm{Fc}$ fragment and $2 \mathrm{Fab}$ fragments as opposed to pepsin treatment which results in the generation of $1 \mathrm{Fc}$ and $1 \mathrm{~F}(\mathrm{ab})_{2}$ fragment. Papain digestion was preferred because $2 \mathrm{Fab}$ fragments should mask more $\mathrm{CD} 38$ antigens than $1 \mathrm{~F}(\mathrm{ab})_{2}$ fragment. In addition, we supposed that the smaller Fab molecules would better bind to $\mathrm{CD} 38$ than the larger $\mathrm{F}(\mathrm{ab})_{2}$ fragment. Moreover, antibodies against light chains in the ID-Card LISS/ Coombs we use in routine diagnostics may bind better to $\mathrm{F}(\mathrm{ab})_{2}$ fragments than to Fab fragments, thereby imitating the presence of an alloantibody. We suspected that Fab fragments would be less prone to this unfavorable interference.

Flow cytometry was used to analyze whether there might be an individual-specific percentage of RBCs with higher expression of CD38 prone to antibody-mediated degradation and which also might be responsible for the positive IAT. We wanted to exclude that young RBCs, for example, might express high levels of CD38 while CD38 is downregulated in older RBCs. However, the scatter plots demonstrated a homogenous expression of CD38 on RBCs of a certain patient or certain donor of test cells. In addition, these investigations demonstrated different CD38 densities on the surface of RBCs between different patients' RBCs or ID panel cells.

In a few panel cells, CD38 density was below the detection limit of flow cytometry, and this was associated with a missing reaction in IAT. Cells with weakly positive IAT 
showed also a low MFI in flow cytometry arguing for a very low antigen density. An MFI of about 100 was associated with a reaction strength of $2+$. The mean number of CD38 molecules per CD8+ T lymphocyte in blood was reported to be about 2,000 in healthy subjects [16]. Considering the comparison of MFI values between CD8+ lymphocytes and erythrocytes in our analyses, we estimated the CD38 density to be about 200 molecules per RBC. To sum up, flow cytometry experiments showed a homogenous expression of CD38 with varying density on patients' and antibody identification cells, and it showed a correlation of CD38 density to the reactivity of test cells in IAT.

Elimination half-life of DARA averages at $110 \pm 42 \mathrm{~h}$ after the first full dose and $587 \pm 487 \mathrm{~h}$ in case of administration of $16 \mathrm{mg} / \mathrm{kg}$ DARA after the seventh last infusion [17]. Therefore, panreactivity can persist up to several weeks after the last DARA application depending on the doses administered, antibody adsorption on blood cells expressing CD38, absorption in the tissue, and the number of blood transfusions a patient has received during or after DARA therapy. Persistence of DARA antibodies was demonstrated with plasma from a patient that induced strong $2+$ reactions in screening cells 7 weeks after the last DARA administration (Fig. 4).

Serial dilution of DARA in SHP revealed agglutination of RBCs when a concentration as low as $12.2 \mu \mathrm{g} / \mathrm{L}$ DARA was added to screening cells. Strong $2+$ reactions were visible for concentrations $\geq 97.7 \mu \mathrm{g} / \mathrm{L}$. No agglutination of RBCs was observed at a DARA concentration of 6.1 $\mu \mathrm{g} / \mathrm{L}$ (Fig. 1). This is in line with the findings of Oostendorp et al. [13] who reported no agglutination when applying DARA at a concentration $\leq 10 \mu \mathrm{g} / \mathrm{L}$. These data and further pharmacodynamic data [17] explain the persistence of DARA interference several weeks after drug administration (Fig. 4).

We started Fab testing using plasma concentrations of 100, 250, and $500 \mathrm{mg} / \mathrm{L}$ DARA since 214 and $575 \mathrm{mg} / \mathrm{L}$ are described as mean predose serum concentrations at the end of weekly dosing after administration of 8 and 16 $\mathrm{mg} / \mathrm{kg}$ DARA, respectively [17]. Our nephelometric measurements directly before DARA application $(16 \mathrm{mg} / \mathrm{kg})$ and on the next day showed an exclusive increase in $\operatorname{IgG}_{1}$ concentration ranging from 200 to $400 \mathrm{mg} / \mathrm{L}$. However, higher peak serum concentrations of 426-993 mg/L can occur directly after administration. Therefore, we additionally tested DARA-Fab with plasma containing a final concentration of $1,000 \mathrm{mg} / \mathrm{L}$ DARA. As expected from prior dilution series, all 4 concentrations resulted in similar $2+$ reactions without treatment and could be abolished completely when cells were simultaneously incubated with DARA-Fab fragments in IAT. Most experiments presented here were performed using $500 \mathrm{mg} / \mathrm{L}$ to show DARA-Fab efficiency in case of high mean predose DARA plasma concentrations.

Daratumumab Fab Fragment Preparation for Pretransfusion Testing
Prevention of RBC agglutination by DARA-Fab (Fig. 3-6) also demonstrates that DARA-Fab fragments which displace DARA from CD38 in a competitive way do not lead to RBC agglutination by interaction with antihuman globulin in the microcolumn gel matrix. The IDCard LISS/Coombs contain polyspecific IgG antisera which means that antibodies against $\kappa$ and $\lambda$ light chains should be present in the microcolumn gel and might lead to RBC agglutination by binding to DARA-Fab. However, the anti-light chain activity in IAT was shown to be too low to cause a false-positive RBC agglutination (Fig. 3).

The main disadvantage of DTT treatment of test cells, which is the current standard procedure in case of DARA-induced panagglutination, is the destruction or modification of other blood group antigens. Therefore, alloantibodies against these blood groups might be overlooked. In contrast, DARA-Fab treatment does not interfere with antibody screening or identification as demonstrated with plasma from patients containing antiE and anti-K alloantibodies (Fig. 6). Spiking of plasma with DARA induced panagglutination of screening cells, which could be prevented by the addition of DARA-Fab to the incubation tube.

Agglutination of RBCs was visible down to a very low antibody concentration of $12.2 \mu \mathrm{g} / \mathrm{L}$ DARA in SHP on ID-Cards LISS/Coombs because the sensitivity of IDCards LISS/Coombs is very high. Only 100-500 bound IgG molecules per cell are sufficient to induce an agglutination in IAT.

Using $50 \mu \mathrm{L}$ of $0.8 \%$ erythrocyte solution $(0.08 \times$ $10^{12} / \mathrm{L}$ ) and $25 \mu \mathrm{L}$ plasma, spiked with $12.2 \mu \mathrm{g} / \mathrm{L}$ DARA (molecular weight $148 \mathrm{kDa}$ ), about 300 DARA antibodies per RBC are incubated enabling visible agglutination. In healthy individuals, the expression of about 2,000 CD38 molecules per CD8 $+\mathrm{T}$ lymphocyte has been described [16]. On RBCs, CD38 is expressed at much lower levels. Our experiments using flow cytometry showed a factor of about 10 so that one could assume a number of about 200 CD38 molecules per RBC. We digested 2 mg DARA collecting the DARA-Fab in $600 \mu \mathrm{L}$ buffer. Assuming a DARA-Fab yield of $>50 \%$, we use DARA-Fab in $4-$ to 8 -fold excess to the number of DARA antibodies when adding $15 \mu \mathrm{L}$ DARA-Fab to erythrocytes and $25 \mu \mathrm{L} 500$ $\mathrm{mg} / \mathrm{L}$ DARA. Regarding the excess of DARA antibodies $\left(1.3 \times 10^{7}\right.$ antibodies/cell $)$ and DARA-Fab fragments $\left(>5 \times 10^{7}\right.$ DARA-Fab/cell) used, presumably all CD38 molecules will bind one of these molecules with similar binding affinities in a competitive manner. If $<100$ CD38 antigens per cell are bound by DARA, the ID-Card LISS/ Coombs system will not be able to detect these few bound antibodies as mentioned above. Therefore, $15 \mu \mathrm{L}$ are sufficient to prevent agglutination in most cases. In case of persisting low agglutination reactions $(<1+)$, increasing the ratio of DARA-Fab fragments to DARA antibodies by 
increasing DARA-Fab volume to $30 \mu \mathrm{L}$ helps to override DARA-induced agglutination and enables identification of even a weak alloantibody reaction. In addition to these considerations, we used a modified pipetting scheme which considers the higher dilution of test cells and DARA antibodies by an increased DARA-Fab volume. However, also these experiments with various alloantibodies showed no detectable impairment of the detection strength of alloantibodies by DARA-Fab. The competitive mode of action of DARA-Fab is in accordance with these findings.

Monoclonal antibodies will be of increasing importance for therapy in oncoming years, and it might be that these antibodies under development also may interact with routine blood compatibility testing. Murphy et al. [18] strongly recommended that one may pay attention to a possible effect of new therapeutics on serological test- ing during drug development or phase 1 studies. In case of monoclonal antibodies with reactivity against RBCs, the procedure proposed in the present paper might also be appropriate.

In summary, this investigation describes a cost-efficient and easy-to-use method for Fab preparation. Moreover, the study demonstrates that Fab fragments may override complications in antibody screening and identification by therapeutic monoclonal antibodies reacting with RBCs in pretransfusion testing without any negative effect on alloantibody detection.

\section{Disclosure Statement}

The authors declare that they have no competing interests.

\section{References}

1 Tzogani K, Penninga E, Schougaard Christiansen ML, Hovgaard D, Sarac SB, et al. EMA Review of Daratumumab for the Treatment of Adult Patients with Multiple Myeloma. Oncologist. 2018 May;23(5):594-602.

2 de Weers M, Tai YT, van der Veer MS, Bakker JM, Vink T, Jacobs DC, et al. Daratumumab, a novel therapeutic human CD38 monoclonal antibody, induces killing of multiple myelo$\mathrm{ma}$ and other hematological tumors. J Immunol. 2011 Feb;186(3):1840-8.

3 Lokhorst HM, Plesner T, Laubach JP, Nahi H, Gimsing P, Hansson M, et al. Targeting CD38 with daratumumab monotherapy in multiple myeloma. N Engl J Med. 2015 Sep;373(13): 1207-19.

4 Oberle A, Brandt A, Alawi M, Langebrake C, Janjetovic S, Wolschke C, et al. Long-term CD38 saturation by daratumumab interferes with diagnostic myeloma cell detection. Haematologica. 2017 Sep;102(9):e368-70.

5 McCudden C, Axel AE, Slaets D, Dejoie T, Clemens P, Frans S, et al. Response to: interference of daratumumab on the serum protein electrophoresis. Clin Chem Lab Med. 2017 Feb;55(2):e29-30.

6 Sullivan HC, Gerner-Smidt C, Nooka AK, Arthur CM, Thompson L, Mener A, et al. Daratumumab (anti-CD38) induces loss of CD38 on red blood cells. Blood. 2017 Jun;129(22): 3033-7.
7 Chapuy CI, Nicholson RT, Aguad MD, Chapuy B, Laubach JP, Richardson PG, et al. Resolving the daratumumab interference with blood compatibility testing. Transfusion. 2015 Jun;55(6 Pt 2):1545-54.

8 Chapuy CI, Aguad MD, Nicholson RT, AuBuchon JP, Cohn CS, Delaney M, et al; DARA-DTT Study Group* for the BEST Collaborative. International validation of a dithiothreitol (DTT)-based method to resolve the daratumumab interference with blood compatibility testing. Transfusion. 2016 Dec; 56(12):2964-72.

9 Quach H, Benson S, Haysom H, Wilkes AM, Zacher N, Cole-Sinclair M, et al. Considerations for pre-transfusion immunohaematology testing in patients receiving the antiCD38 monoclonal antibody daratumumab for the treatment of multiple myeloma. Intern Med J. 2018 Feb;48(2):210-20.

10 Sigle JP, Mihm B, Suna R, Bargetzi M. Extending shelf life of dithiothreitol-treated panel RBCs to 28 days. Vox Sang. 2018 May;113(4): 397-9.

11 Lorenzen $\mathrm{H}$, Lone Akhtar $\mathrm{N}$, Nielsen $\mathrm{M}$, Svendsen L, Andersen P. Thirty-three-day storage of dithiothreitol-treated red blood cells used to eliminate daratumumab interference in serological testing. Vox Sang. 2018 Oct;113(7):686-93.

12 Carreño-Tarragona G, Cedena T, Montejano L, Alonso R, Miras F, Valeri A, et al. Papaintreated panels are a simple method for the identification of alloantibodies in multiple myeloma patients treated with anti-CD38based therapies. Transfus Med. 2018 Jan 25. doi.org/10.1111/tme.12508.
13 Oostendorp M, Lammerts van Bueren JJ, Doshi P, Khan I, Ahmadi T, Parren PW, et al. When blood transfusion medicine becomes complicated due to interference by monoclonal antibody therapy. Transfusion. 2015 Jun; 55(6 Pt 2):1555-62.

14 Selleng K. Positiver indirekter Antihumanglobulintest durch Daratumumab - Strategien für die transfusionsmedizinische Versorgung. Transfusionsmedizin. 2016;6(02):70-5.

15 Schneeweiß C, Grüger D, Heuft HG. DaraEx verhindert Daratumumab-Interferenz im indirekten Antihumanglobulintest. Transfusionsmedizin. 2017;7(04):229-32.

16 Benito JM, López M, Lozano S, Martinez P, González-Lahoz J, Soriano V. CD38 expression on CD8 $\mathrm{T}$ lymphocytes as a marker of residual virus replication in chronically HIVinfected patients receiving antiretroviral therapy. AIDS Res Hum Retroviruses. 2004 Feb; 20(2):227-33.

17 European Medicine Agency (EMA). Assessment Report. Darzalex. London: EMA; 2016. EMA/278085/2016, EMA/278085/2016.

18 Murphy MF, Dumont LJ, Greinacher A; BEST Collaborative. Interference of New Drugs with Compatibility Testing for Blood Transfusion. N Engl J Med. 2016 Jul;375(3): 295-6. 